\title{
Interspinous Ligament Lidocaine and Steroid Injections for the Management of Baastrup's Disease: A Case Series
}

\author{
Kentaro Okada, Seiji Ohtori, Gen Inoue, Sumihisa Orita, Yawara Eguchi, Junichi Nakamura, \\ Yasuchika Aoki, Tetsuhiro Ishikawa, Masayuki Miyagi, Hiroto Kamoda, Miyako Suzuki, \\ Gou Kubota, Yoshihiro Sakuma, Yasuhiro Oikawa, Kazuhide Inage, Takeshi Sainoh, \\ Tomoaki Toyone, Kazuyo Yamauchi, Kazuhisa Takahashi
}

Department of Orthopaedic Surgery, Graduate School of Medicine,Chiba University, Chuo-ku, Japan

\begin{abstract}
Study Design: Prospective study.
Purpose: To examine the long-term effects of interspinous ligament injections of local anesthetics and steroids for the treatment of Baastrup's diseases.

Overview of Literature: Baastrup's disease is associated with axial low back pains. Baastrup's disease has been more recently described as the "kissing spinous processes" disease. Several authors have reported methods for the diagnosis and treatment of the disease. However, there has been only one report of patients receiving interspinous ligament injections of agents for the treatment of Baastrup's disease.

Methods: Seventeen patients showed severe low back pains between spinous processes at L3-L4 or L4-L5. X-ray imaging, computed tomography, and magnetic resonance imaging revealed kissing spinous processes, consolidation of spinous process, or inflammation of an interspinous ligament. Pain reliefs after lidocaine and dexamethasone administration into interspinous ligament as therapy for low back pains were being examined and followed up.

Results: Low back pain scores significantly improved immediately after injection of the agents into interspinous ligaments. At final follow-up (1.4 year), low back pain scores significantly improved as compared with before the treatment.

Conclusions: Findings from the current study indicate that lidocaine and dexamethasone administration into interspinous ligament in patients diagnosed with Baastrup's disease is effective for managing the pain associated with this disease.
\end{abstract}

Keywords: Pain; Local anesthetic; Steroid

\section{Introduction}

Mayer [1], Brailsford [2], and Baastrup [3] have described a condition of pathological changes in the opposing surfaces of adjacent spinous processes and the soft tissues between them within the lumbar spine. This condition induces low back pain in some patients and is known as the Baastrup's disease. It is characterized on imaging by contacts between adjacent lumbar spinous processes ("kissing spine"). Radiographical findings include sclero-

Received Jan 17, 2013; Revised Mar 10, 2013; Accepted Jun 2, 2013

Corresponding author: Seiji Ohtori

Department of Orthopaedic Surgery, Graduate School of Medicine, Chiba University,

1-8-1 Inohana, Chuo-ku, Chiba 260-8670, Japan

Tel: +81-43-226-2117, Fax: +81-43-226-2116, E-mail: sohtori@faculty.chiba-u.jp 
sis, enlargement, and flattening of the appositional surfaces [1-3].

Various methods of therapy for Baastrup's diseases have been considered including the resection of spinous processes. To our knowledge, there have been reports of only 4 patients who have received non-surgical treatments of local anesthetics and steroid injections into interspinous ligaments for Baastrup's diseases [4,5]. Furthermore, the period of follow-up was short.

Therefore, the purpose of the current study is to evaluate the long-term effects of injections of steroid and local anesthetics into interspinous ligaments for the treatment of Baastrup's disease in 17 patients.

\section{Materials and Methods}

The ethics committee of our institution approved the protocols for the human procedures used in this study. This report was also approved by the patients after informed consents.

\section{Patients}

Seventeen patients were presented with low back pains, but without associated leg pains, which continued for at least 4 months. Patients showed severe low back pains. The area of low back pain was shown to be localized to between spinous processes. Patients were diagnosed on $\mathrm{X}$-ray examination, computed tomography (CT), and magnetic resonance imaging (MRI). Profile views of Xray examinations at normal, flexion, and extension positions were performed. CT was also performed to evaluate bone consolidation of spinous processes. Edema and inflammation of interspinous ligaments was evaluated by MRI (T1- and T2-weighted images). If a patient showed low back pains localized between spinous processes and at least one of the following imaging findings included 1) contact and consolidation of spinous processes on $\mathrm{X}$-ray films, and 2) contact and consolidation of spinous processes on CT, and/or edema and inflammation of interspinous ligaments as evaluated by MRI, we defined the patient's disease as Baastrup's disease. Details of patients' backgrounds and pain scores are shown in Table 1.

\section{Pain score before and after treatment (final follow-up)}

We evaluated low back pains and leg pains in the patients
Table 1. Demographic characteristics

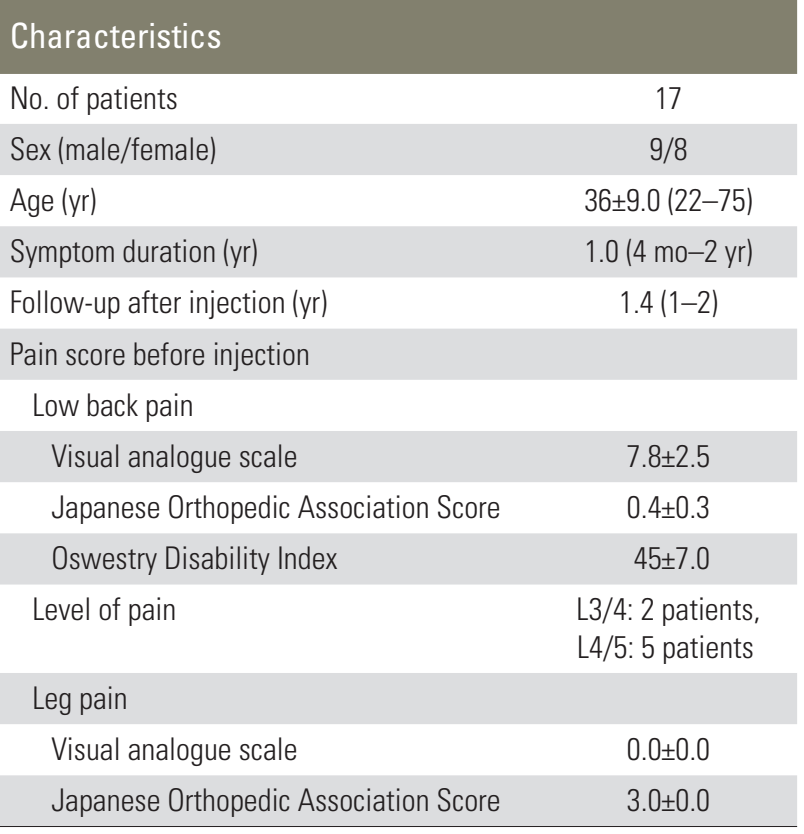

Values are presented as number or mean (range).

before and after the injection of lidocaine and dexamethasone into their interspinous ligaments (final follow-up). To evaluate their pain scores, a visual analogue scale (VAS) score ( 0 , no pain; 10 , worst pain), Japanese Orthopedic Association Score (JOAS; 0, worst pain; 3, no pain), and Oswestry Disability Index (ODI) were recorded before and after the injections.

\section{Subjective outcomes}

At final follow-up (average, 1.4 years; range, 1-2 years), patients were asked to choose one of the following responses regarding their satisfaction with the treatment according to criteria adopted by the North American Spine Society Low Back Outcome Instrument: 1) The treatment met my expectations; 2) I did not improve as much as I had hoped, but I would undergo the same treatment for the same outcome; 3) The treatment helped, but I would not undergo the same treatment for the same outcome; or 4) I remained the same as or worse than I was before the treatment [6].

\section{Injection of local anesthetic and steroid into inter- spinous ligaments}

The patients received an infiltration of lidocaine and 
dexamethasone into their interspinous ligaments. A 24-gauge spinal-nerve-block needle was advanced into their painful interspinous ligaments under fluoroscopic control. Then, a $0.5 \mathrm{~mL}$ of the contrast medium Iotorolan (Schering AG, Berlin, Germany) was injected to confirm the position of the interspinous ligament. Lidocaine (2.0 $\mathrm{mL}$ of $1 \%$ solution) and dexamethasone $(1 \mathrm{~mL}$ of $3.3 \mathrm{mg} /$ $\mathrm{mL}$ ) administration was also performed. The intensity of low back pain was evaluated before the block using a VAS (score, $0-10$; a score of 10 being the worst pain). At 30 minutes after the first infiltration, the VAS scores were reexamined and compared with scores before infiltration. We defined the treatment as "effective" if patients indicated less than $60 \%$ of their initial VAS score at 30 minutes. If the patients desired an additional injection, further administration of lidocaine was given at an interval of 7 days.

\section{Statistical analysis}

Data were compared using a Mann-Whitney $U$ test. $p<0.05$ was considered statistically significant.

\section{Results}

\section{Demographic characteristics}

Table 1 shows demographic characteristics in patients. The pain score was severe in all patients. The patients only showed low back pains in the area between spinous processes. The levels were L3-L4 in 7 patients and L4-L5 in 10 patients.

\section{Evaluation of X-ray imaging, CT, and MRI}

Table 2 shows evaluation by X-ray imaging, CT, and MRI. $\mathrm{X}$-ray imaging profile views revealed the contact of both spinous processes within a normal position in 7 patients, contact at an extension position (without contact at a normal position) in 4 patients, and mostly contact in an extension position in 6 patients. CT findings showed no changes in spinous processes of 8 patients, and consolidation of spinous processes of 9 patients. MRI was normal for 10 patients. However, low signal intensity on T1-weighted images and high signal intensity on T2weighted images in interspinous ligaments was shown in 7 patients.
Table 2. Evaluation of X-ray, computed tomography, and magnetic resonance imaging

\begin{tabular}{lc} 
Characteristics & Patients \\
X-ray & \\
\hline Contact at normal position & 7 \\
Contact at extension position & 4 \\
Mostly contact at extension position & 6 \\
\hline Computed tomography & \\
\hline Normal & 8 \\
\hline Consolidation & 9 \\
\hline Magnetic resonance imaging & 10 \\
\hline Normal & \\
\hline T1 low, T2 high7 &
\end{tabular}

Table 3. Evaluation of low back pain after injection

Characteristics

Pain score after injection

\begin{tabular}{|c|c|}
\hline Low back pain & \\
\hline Visual analogue scale & $2.8 \pm 1.5$ \\
\hline Low back pain & $\mathrm{n}=17$ \\
\hline $100 \%$ Pain relief after injection & 4 \\
\hline $80 \%-99 \%$ Pain relief after injection & 9 \\
\hline $60 \%-79 \%$ Pain relief after injection & 4 \\
\hline $40 \%-59 \%$ Pain relief after injection & 0 \\
\hline 20\%-39\% Pain relief after injection & 0 \\
\hline 0\%-19\% Pain relief after injection & 0 \\
\hline
\end{tabular}

\section{Evaluation of low back pain $\mathbf{3 0}$ minutes after injection of lidocaine and dexamethasone}

Table 3 shows results from evaluation of low back pains 30 minutes after injection of lidocaine and dexamethasone. VAS 30 minutes after injection was $2.8 \pm 1.5$, and significantly less than before injection. After injections of lidocaine and dexamethasone into the interspinous ligament, all patients showed "effective" treatments.

\section{Evaluation of low back pain 1.4 year after injection of lidocaine and dexamethasone (final follow-up)}

The average number of lidocaine and dexamethasone injections was 4.0 \pm 1.5 (range, 3-6). VAS score, JOAS, and ODI significantly improved after injection when compared with before treatment as shown in Tables 1, 4 
Table 4. Low back pain scores 1.4 year after multiple-injection

\begin{tabular}{|c|c|}
\hline \multicolumn{2}{|l|}{ Characteristics } \\
\hline Number of injection (time) & $4.0 \pm 1.5(3-6)$ \\
\hline \multicolumn{2}{|l|}{ Pain score after injection } \\
\hline \multicolumn{2}{|l|}{ Low back pain } \\
\hline Visual analogue scale & $2.0 \pm 0.5$ \\
\hline Japanese Orthopedic Association Score & $2.5 \pm 0.5$ \\
\hline Oswestry Disability Index & $10 \pm 7$ \\
\hline \multicolumn{2}{|l|}{ Leg pain } \\
\hline Visual analogue scale & $0.0 \pm 0.0$ \\
\hline Japanese Orthopedic Association Score & $3.0 \pm 0.0$ \\
\hline \multicolumn{2}{|l|}{ Subjective outcomes (no. of patients) } \\
\hline 1) Treatment met my expectations & 15 \\
\hline 2) I did not improve as much as I had hoped, but I would undergo the same treatment for the same outcome & 2 \\
\hline 3) Treatment helped, but I would not undergo the same treatment for the same outcome & 0 \\
\hline 4) I am the same as or worse than I was before the treatment & 0 \\
\hline
\end{tabular}

Values are presented as mean (range) or number.

$(p<0.01)$. Subjective outcome evaluated from patients was good in 15 patients. Leg pain was not observed during the follow-up period in any patient. Surgery was not required for any patient. Case presentations were shown in Figs. 1, 2.

\section{Discussion}

In the current study, we evaluated the long-term effects of interspinous ligament injections of lidocaine and dexamethasone for the treatment of Baastrup's disease in 17 patients. Findings from the current study indicate that lidocaine and steroid administration into interspinous ligaments of patients diagnosed with Baastrup's disease is effective for the management of pains associated with this disease.

Some authors have reported that pathological changes in opposing surfaces of adjacent spinous processes and the soft tissues between them in the lumbar spine could induce low back pains for some patients. However, the precise method of diagnosis has not yet been fully explored. Several authors have reported imaging such as CT, MRI, and 18F-fluorodeoxyglucose-positron emission tomography for diagnosis of Baastrup's diseases [4,710]. CT showed that sclerosis at the superior and inferior edges of lumbar spinous processes was associated with profound fatty tissue replacements of the paraspinal musculature [8]. Moreover, an electromyography report showed severe isolated paraspinal denervation [8]. MRI findings have included remarkably edematous and inflammatory changes around spinous processes with cystic degeneration (geode formation) of the spinous processes [4]. Edematous and inflammatory changes extended into the interspinous ligaments [4]. Lumbar interspinous bursitis was shown to be present in 8.2\% (44 of 539) of 539 consecutive patients undergoing routine lumbar spine MRI for back pains or leg pains [10]. This suggests limitations for the diagnosis of painful Baastrup's disease using MRI. The diagnosis of Baastrup's disease using bone single-photon emission computed tomography has been previously reported [9]. 18F-fluorodeoxyglucose-positron emission tomography uptake between the spinous processes, secondary to Baastrup's disease has been reported and knowledge of this pattern of uptake is helpful in diagnosing the Baastrup's disease [7]. In the current study, CT findings showed consolidation of spinous processes in 4 patients and MRI showed low signal intensity on T1weighted images and high signal intensity on T2-weighted images of interspinous ligaments in 2 patients. We concluded that specific imaging was useful for diagnosis of some patients.

Injection of agents into the interspinous ligament for the treatment of Baastrup's disease has been reported for 4 patients by 2 different authors [4,5]. Lamer et al. [4] 

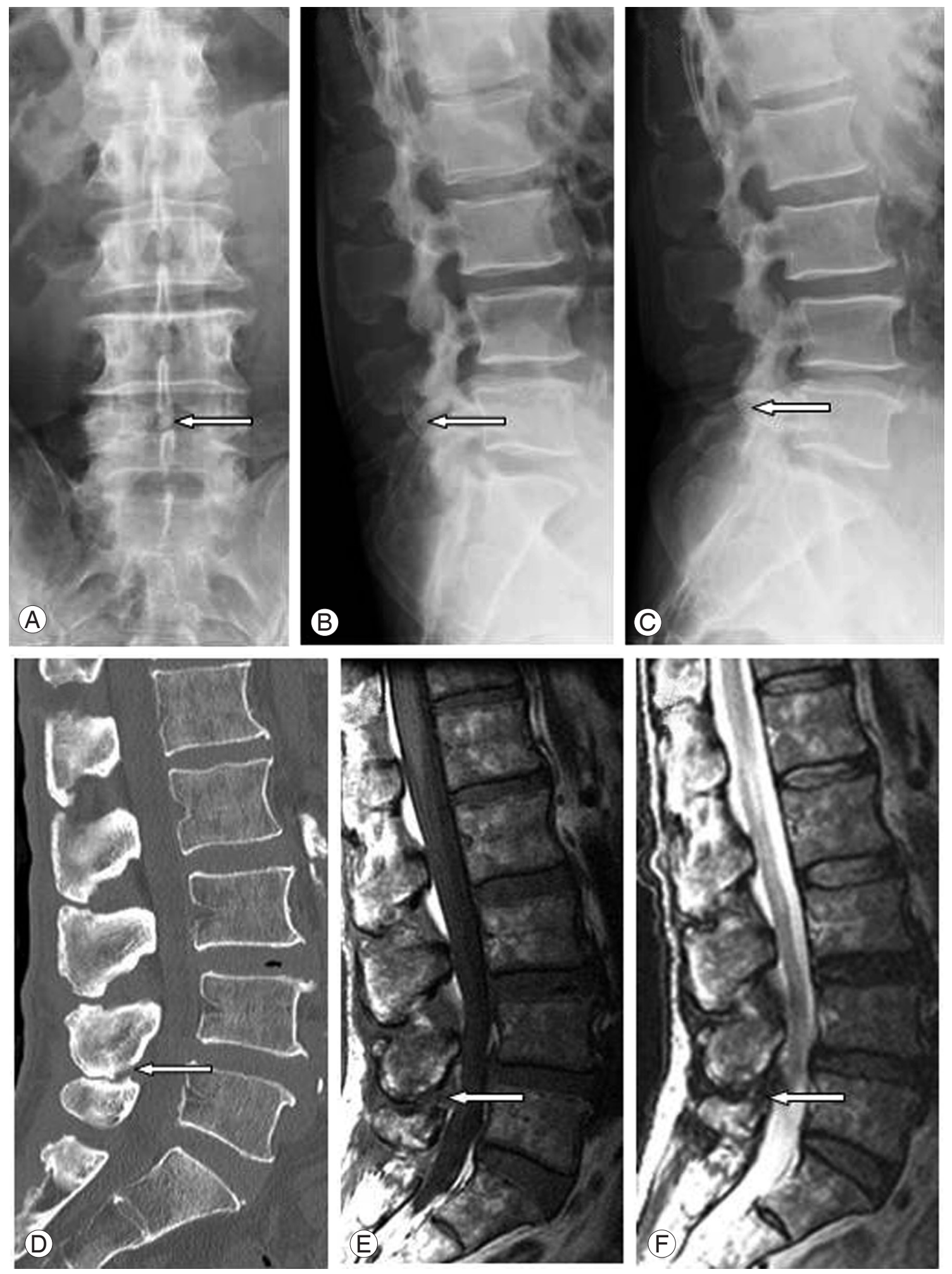

Fig. 1. A 65-year-old man with severe low back pains between spinous processes. (A) X-ray films show "kissing spine" on Anterior-Posterior-views (arrow). (B) Profile view showed that these spinous processes did not contact in flexion position, (C) but was contacted in extension position (arrows). (D) Computed tomography revealed spinous process contact and consolidation (arrow). Magnetic resonance imagingshowed no changes in signal intensity of the interspinous ligament on T1-(E) or T2-(F) weighted images (arrow). The pain decreased after injections of lidocaine and dexamethasone into the interspinous ligament. 

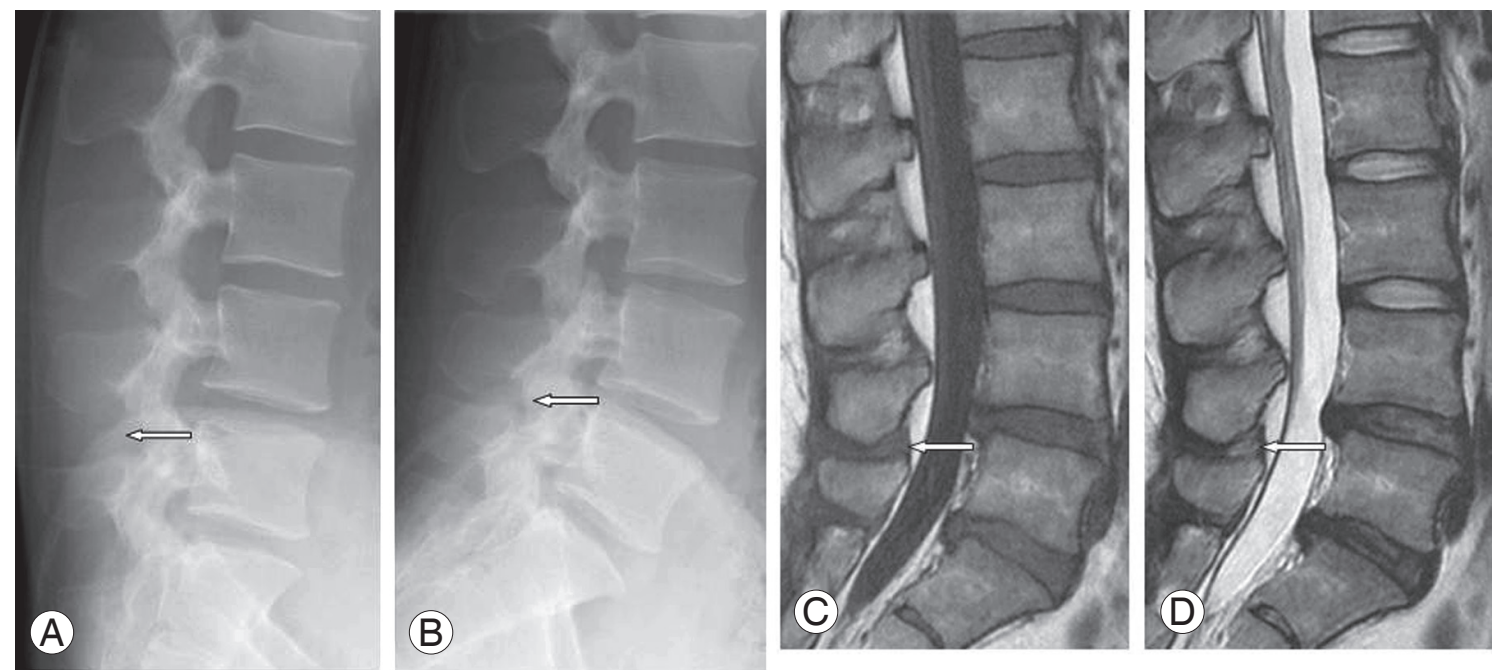

Fig. 2. A 24-year-old man with severe low back pains between spinous processes. (A) Profile view of X-ray films showed that these spinous processes did not contact in flexion position, (B) but did contact in extension position (arrows). (C) Magnetic resonance imaging showed low signal intensity on T1-weighted imagesand (D) high signal intensity on T2-weighted imagesof the interspinous ligament (arrows). The pain decreased after injection of lidocaine and dexamethasone into the interspinous ligament.

reported 3 patients with MRI findings consisting of inflammation or edema, or both, in the spinous processes and surrounding soft tissues. Fluoroscopically-guided injections of bupivacaine and betamethasone provided pain relief in all 3 patients. Two patients were treated on 2 separate occasions, approximately 3 weeks apart. The pain reduction was observed at 4 and 6 months of follow-up. One patient with recurrent pain eventually underwent successful surgical resection of the involved spinous processes. Mitra et al. [5] presented a simple case report of an 89-year-old woman with symptomatic Baastrup's disease. The patient underwent a fluoroscopically guided interspinous single injection of $20 \mathrm{mg}$ of triamcinolone acetate with local anesthetic. The patient remained pain-free for 3 months. In the current study, we used multiple injections of lidocaine and dexamethasone, and showed at least 1 year of pain relief, and experienced no requirements for surgery in any cases. We concluded that fluoroscopically guided injection of lidocaine and dexamethasone into the interspinous processes is useful for the management of low back pains originating from the touching surfaces of adjacent spinous processes. Steroids should be considered to be effective if injected to the bursa between the interspinous spaces. However, there is a possibility of interspinous ligament attenuation or weakness after steroid injections. We need longer term of follow-up to evaluate this point.

It is important to distinguish between painful Baas- trup's disease and other painful diseases. It has been reported that 10 patients undergoing surgical excision of spinous processes for Baastrup's disease demonstrated improvements [11]. On the other hand, surgical excision of spinous processes for Baastrup's disease in 64 patients demonstrated that surgery does not always alleviate a patient's pain [12]. Therefore, further investigation for the diagnosis of this disease is needed.

\section{Conclusions}

We evaluated long-term effects of interspinous ligament injections of lidocaine and dexamethasone for the treatment of Baastrup's disease in 17 patients. Findings of the current study indicate lidocaine and dexamethasone administration into the interspinous ligaments of patients diagnosed with Baastrup's disease is effective for management of the pains associated with this disease.

\section{Conflict of Interest}

No potential conflict of interest relevant to this article was reported.

\section{References}

1. Mayer. Ueber zwei neu entdeckte Gelenke an der Wirbelsäule des menschlichen Korpers. Z Physiol 
1825;2:29-35.

2. Brailsford JF. Deformities of the lumbosacral region of the spine. Br J Surg 1929;16:562-627.

3. Baastrupt CI. Proc. spin. vert. lumbUnd einige zwischen diesen liegende Gelenkbildungen mit pathologischen Prozessen in dieser Region. Rofo 1933;48:430-5.

4. Lamer TJ, Tiede JM, Fenton DS. Fluoroscopicallyguided injections to treat "kissing spine" disease. Pain Physician 2008;11:549-54.

5. Mitra R, Ghazi U, Kirpalani D, Cheng I. Interspinous ligament steroid injections for the management of Baastrup's disease: a case report. Arch Phys Med Rehabil 2007;88:1353-6.

6. Wood EG III, Hanley EN Jr. Lumbar disc herniation and open limited discectomy: Indications, techniques, and results. Oper Tech Orthop 1991;1:23-8.
7. Lin E. Baastrup's disease (kissing spine) demonstrated by FDG PET/CT. Skeletal Radiol 2008;37:173-5.

8. Haig AJ, Harris A, Quint DJ. Baastrup's disease correlating with diffuse lumbar paraspinal atrophy: a case report. Arch Phys Med Rehabil 2001;82:250-2.

9. Hamlin LM, Delaplain CB. Bone SPECT in Baastrup's disease. Clin Nucl Med 1994;19:640-1.

10. Maes R, Morrison WB, Parker L, Schweitzer ME, Carrino JA. Lumbar interspinous bursitis (Baastrup disease) in a symptomatic population: prevalence on magnetic resonance imaging. Spine (Phila Pa 1976) 2008;33:E211-5.

11. Franck S. Surgical treatment of intraspinal osteoarthrosis (kissing spine). Acta Orthop Scand 1944;14:127-52.

12. Beks JW. Kissing spines: fact or fancy? Acta Neurochir 1989;100:134-5. 